\title{
Efficacy of structured teaching programme on home care management of pregnancy induced hypertension in primigravida mothers: a tertiary hospital study
}

\author{
Neelima Singh $^{1 *}$, Satyendra Nath Ponna ${ }^{1}$, K. Rani Rajeshwari ${ }^{2}$
}

\author{
${ }^{1}$ Technical Support Unit, Maternal and Child Health, Indian Institute of Health and Family Welfare, Hyderabad, \\ Telangana, India \\ ${ }^{2}$ Nursing Officer, Primary Health Centre, Alladurg, Medak, Telangana, India
}

Received: 16 July 2017

Accepted: 20 July 2017

\author{
*Correspondence: \\ Dr. Neelima Singh, \\ E-mail: singh.neelima.18@gmail.com
}

Copyright: () the author(s), publisher and licensee Medip Academy. This is an open-access article distributed under the terms of the Creative Commons Attribution Non-Commercial License, which permits unrestricted non-commercial use, distribution, and reproduction in any medium, provided the original work is properly cited.

\begin{abstract}
Background: Hypertensive disease of pregnancy is one of the major causes of maternal mortality in India. $7.1 \%$ of maternal deaths are attributed to hypertension disorder of pregnancy. Early identification of modifiable and nonmodifiable risk factors of hypertensive disorders of pregnancy is essential for effective management of hypertensive disease of pregnancy. The study assesses the knowledge of primigravida women regarding home care management of pregnancy induced hypertension before and after administering structured teaching programme.

Methods: It is a pilot study with pre-experimental study design. 30 study participants were recruited with nonprobability purposive sampling of primigravida women attending antenatal clinic of maternity hospital of Petlaburj, Hyderabad. A pretested and standardized survey instrument was used for collecting socio-demographic characteristics and knowledge, attitude and practices regarding home care management of pregnancy after obtaining informed consent before and after structured teaching intervention programme with audio-visual aids for home management of pregnancy induced hypertension.

Results: $43.3 \%$ of primigravida women were $21-24$ years old and $43.3 \%$ of primigravida women were $20-24$ years of gestation. Mean pre-test and post-test knowledge assessment score increased by $155.2 \%$ from 13.4 to 34.2 after administration of structured teaching programme and paired-t test was carried out to test difference of means. The test reports t-test statistic of -20.7 with p-value of $<0.001$ is highly significant.

Conclusions: Evidence based guidelines adopted by Government of India should be implemented by health facilities by upgrading infrastructure, capacity building and community engagement for early identification of complications of pregnancy to seek health care services.
\end{abstract}

Keywords: Knowledge, Pregnancy induced hypertension, Primigravida

\section{INTRODUCTION}

Hypertensive disorder of pregnancy is one of the major causes of maternal mortality in India. It comprises preeclampsia, eclampsia, gestational hypertension and chronic hypertension. WHO multi country survey reveals incidence of gestational hypertension (4.4\%), preeclampsia (3\%), eclampsia $(0.8 \%)$ and chronic hypertension $(0.1 \%)$ in India. ${ }^{1}$ While hospital incidence of hypertensive disease of pregnancy is $7.8 \%$ in Bharati Hospital and Research Centre. ${ }^{2}$

Million death study reveal $7.1 \%$ of maternal deaths are attributed to hypertensive disorder of pregnancy. ${ }^{3}$ 
Management of hypertension disorder of pregnancy includes early identification of risk factors of pregnant women and appropriate care during antepartum, intrapartum and postpartum period. Therefore, identification of modifiable risk factors such as anemia, smoking, alcohol consumption and education and nonmodifiable risk factors such as maternal age, primi gravida, multiple pregnancy, past history of hypertensive disease of pregnancy, gestational diabetes mellitus, comorbidities (diabetes mellitus, chronic hypertension and urinary tract infection), family history of HDP and genetic variants is essential for timely intervention by healthcare staff during further course of pregnancy. ${ }^{4}$ Evidence from previous studies reveals incidence of HDP is high in primi gravida women. ${ }^{5-8}$ Primi had $34 \%$ higher risk of HDP compared to multiparous women. ${ }^{5}$ The culture of delayed childbearing is spreading in urban India, might contribute to rise in the future incidence of HDP. It is corroborated by evidence from previous studies, risk of gestational hypertension was $22 \%$ and $63 \%$ higher in 35-39.9 and 40-44.9 years age old compared to 25-29.9 years age old mothers. ${ }^{9}$ Other study findings show that risk of preeclampsia increases by $4 \%$ after 32 years of age for mothers. ${ }^{10}$ HDP with increasing maternal age is due to signs of aging such as low nitric oxide levels and high oxidative stress adversely affecting relaxation of endothelium. ${ }^{11}$

The study assesses the knowledge of primigravida mothers with PIH regarding home care management to prepare and administer structured teaching programme and post-assessment is carried out to determine the efficacy of tool in gaining mothers knowledge. Studies to demonstrate evidence of implementation of such tool at public health facilities are lacking.

\section{METHODS}

The study conducted at Modern Government Maternity Hospital at Petlaburj, Hyderabad. It is one of the maternity hospitals under Osmania Medical College providing tertiary care services to the local population and referral services to the entire state of Telangana. The delivery load is highest in the state with load of 500-600 antenatal-outpatient visits and 50-70 deliveries per day.

\section{Operational definition of Pregnancy Induced Hypertension (PIH)}

Primi gravida mothers with 20-36 weeks of gestation identified with rise of blood pressure more than 140/90 $\mathrm{mm}$ of $\mathrm{Hg}$, without proteinuria and oedema attending antenatal clinic of Modern Government Maternity Hospital, Petlaburj, Hyderabad.

It is a pilot study with pre-experimental study design. Non-probability purposive sampling was used to recruit 30 primigravida mothers diagnosed of PIH. It is a prepost-test study design to assess the efficacy of home care management of PIH among primigravidae by using standardized survey instrument before and after administration of structured teaching programme.

\section{Inclusion criteria}

Primi chosen to minimize confounding factors of associated chronic disease and age.

- Primigravida mothers with 20-36 weeks of gestation attending antenatal clinic of Modern Government Maternity Hospital, Petlaburz, Hyderabad.

- Primigravida mothers diagnosed of PIH.

- Primigravida mothers given consent to participate in the study.

\section{Exclusion criteria}

- $\quad$ Primi mothers without PIH.

- Primi mothers less than 20 weeks and greater than 36 weeks of gestation.

- Primi mothers with or without PIH unwilling to participate in the study.

\section{Data collection}

A pretested and standardized questionnaire was used to collect socio-demographic data and knowledge, attitude and practices regarding home care management of pregnancy. Information was collected about personal habits, family history of hypertension disorders of pregnancy, co-morbidities, knowledge of anatomy and physiology of pregnancy, knowledge of pathophysiology and clinical signs and symptoms of PIH, knowledge regarding homecare management of PIH. The objective of the study was explained to study participants and prior oral and written informed consent was obtained from them.

\section{Intervention tool}

Structured teaching programme was designed to meet the specific objectives of primi mothers to learn classification, definition, diagnostic criteria, aetiology, signs and symptoms, home care management of PIH.

\section{Statistical analysis}

Frequency distribution of socio-demographic and clinical characteristics of primigravidae of 20-36 weeks was performed. Paired-t test was carried out to determine efficacy of structured teaching programme in home care management of PIH. Analysis was carried out using SPSS 20.0 (IBM Corp., Armonk, NY, USA).

\section{RESULTS}

Table 1 reports frequency distribution of sociodemographic characteristics of prim gravidae of 20-36 weeks gestation diagnosed of PIH. 
- $43.3 \%$ of study participants were $21-24$ years old.

- $23.3 \%$ were less than 20 years old.

- $26.7 \%$ were 25-29 years old.

- Most of the study participants had primary education $(43.3 \%)$.

- Secondary education $(23.3 \%)$, graduate and above $(23.3 \%)$.

- $\quad 66.7 \%$ were housewives, $23.3 \%$ were unskilled worker and only $10 \%$ were skilled worker.

- $66.7 \%$ were from households with family income less than Rupees 60,000 per annum.

Table 1: Sociodemographic characteristics of primi mothers.

\begin{tabular}{|c|c|c|}
\hline \multicolumn{2}{|c|}{ Sociodemographic variables } & $\begin{array}{l}\text { Frequency } \\
(\%)\end{array}$ \\
\hline \multirow{4}{*}{$\begin{array}{l}\text { Mother's Age } \\
\text { (Years) }\end{array}$} & $<20$ & $7(23.3)$ \\
\hline & $21-24$ & $13(43.3)$ \\
\hline & $25-29$ & $8(26.7)$ \\
\hline & $>30$ & $2(6.7)$ \\
\hline \multirow{3}{*}{ Religion } & Hindu & $16(53.3)$ \\
\hline & Muslim & $12(40)$ \\
\hline & Christian & $2(6.7)$ \\
\hline \multirow{4}{*}{ Educational Status } & Illiterate & $3(10)$ \\
\hline & Primary & $13(43.3)$ \\
\hline & Secondary & $7(23.3)$ \\
\hline & $\begin{array}{l}\text { Graduate and } \\
\text { above }\end{array}$ & $7(23.3)$ \\
\hline \multirow{3}{*}{$\begin{array}{l}\text { Occupation of } \\
\text { Mother }\end{array}$} & Housewife & $20(66.7)$ \\
\hline & $\begin{array}{l}\text { Unskilled } \\
\text { worker }\end{array}$ & $7(23.3)$ \\
\hline & Skilled worker & $3(10)$ \\
\hline \multirow{4}{*}{$\begin{array}{l}\text { Family Income per } \\
\text { Annum (Rupees) }\end{array}$} & $<60,000$ & $20(66.7)$ \\
\hline & $60,000-90,000$ & $7(23.3)$ \\
\hline & $\begin{array}{l}90,001- \\
1,20,000\end{array}$ & $2(6.7)$ \\
\hline & $>1,20,000$ & $1(3.3)$ \\
\hline
\end{tabular}

$\mathrm{N}=30$. Values are frequencies and proportions

Table 2: Clinical characteristics of primiparous mothers.

\begin{tabular}{|lll|}
\hline \multicolumn{2}{|c|}{ Clinical characteristic } & \multicolumn{1}{l}{$\begin{array}{l}\text { Frequency } \\
(\%)\end{array}$} \\
\hline \multirow{3}{*}{ Family history } & Preeclampsia & $1(3.3)$ \\
& Eclampsia & $1(3.3)$ \\
\cline { 2 - 3 } & No Family Hx of PIH & $28(93.3)$ \\
\hline \multirow{3}{*}{ Comorbidities } & Chronic hypertension & $2(6.7)$ \\
\cline { 2 - 3 } & Diabetes mellitus & $2(6.7)$ \\
\cline { 2 - 3 } & Renal disorder & $2(6.7)$ \\
\cline { 2 - 3 } Gestational age & No past medical Hx & $24(80)$ \\
\hline \multirow{2}{*}{$\begin{array}{l}\text { of mothers } \\
\text { (weeks) }\end{array}$} & $20-24$ & $13(43.3)$ \\
\cline { 2 - 3 } & $25-28$ & $7(23.3)$ \\
\hline
\end{tabular}

$\mathrm{N}=30$. Values are frequencies and proportions
Table 2 reports clinical characteristics of primigravida mothers.

- $3.3 \%$ of study participants had family history of preeclampsia and eclampsia and $93.3 \%$ of them had no family history of hypertension.

- $6.7 \%$ of primigravida mothers were diagnosed of chronic hypertension, diabetes mellitus and renal disorder.

- $\quad 43.3 \%, 23.3 \%$ and $30 \%$ study participants were with 20-24 weeks, 25-28 weeks and 29-32 weeks of gestation respectively.

Table 3 reports descriptive statistics and paired-t test results of pre-test and post-test knowledge scores of the mothers of primi.

Table 3: Descriptive statistics and paired ' $t$ ' test results of knowledge scores.

\begin{tabular}{|lll|}
\hline Statistic & Pre-test & Post-test \\
\hline Mean & 13.4 & 34.2 \\
\hline Median & 13.5 & 35 \\
\hline Mode & 14 & 35 \\
\hline Std. deviation & 3.27 & 2.17 \\
\hline Variance & 10.67 & 4.7 \\
\hline Minimum & 7 & 28 \\
\hline Maximum & 20 & 37 \\
\hline Standard error & 0.60 & 0.40 \\
\hline Paired t-test & - & -20.77 \\
\hline \# p-value $<0.01$ with 29df & & \\
\hline
\end{tabular}

- Mean difference between pre-test and post-test knowledge scores is $20.8 \%$.

- Minimum and maximum score of pre-test knowledge is 7 and 28 while post-test knowledge score is 28 and 37 respectively.

- $\quad$ Paired-t test revealed there is significant difference in pre-test and post-test knowledge score of home care management of PIH with the rejection of null hypothesis.

Table 4: Knowledge scores pre-and post intervention.

\begin{tabular}{|lll|}
\hline Knowledge assessment & $\begin{array}{l}\text { Pretest } \\
\text { score }\end{array}$ & $\begin{array}{l}\text { Posttest } \\
\text { score }\end{array}$ \\
\hline Levels of knowledge & & \\
\hline Below average & 22 & 0 \\
\hline Average & 8 & 1 \\
\hline Above average & 0 & 29 \\
\hline Knowledge score (mean) & 13.43 & 34.2 \\
\hline
\end{tabular}

Values are numerical pre-test and post-test scores

Table 4 reveals 22 and 8 subjects have below average and average pre-test knowledge scores, and 1 and 29 subjects have average and above average post-test knowledge scores. 


\section{DISCUSSION}

The pilot study findings revealed the knowledge gained about PIH assessed by standardized survey instrument to primigravida mothers diagnosed of PIH after the administration of the structured teaching programme on home care management of PIH has improved and found highly significant with ' $t$ ' statistic of 29.70 and $p$ value $<0.001$. The formulated hypothesis of no gain of knowledge of primigravida mothers of PIH after administration of structured teaching programme intervention tool is rejected.

Our findings are corroborated by results from previous study conducted at tertiary hospital at Bhubaneswar, posttest knowledge score of 27.24 compared to pre-test score of 13.96 with mean difference of 13.29 and another study conducted at primary health centre at Mangalore district show mean pre-test score of 9.67 and post test score of 25.47 , increase by $84.9 \% .^{12,13}$

Inadequate antenatal care by following improper protocol of measuring blood pressure and discontinuity in antenatal visits results to higher odds of high systolic blood pressure and diastolic blood pressure, and inappropriate intrapartum care of preeclampsia and eclampsia leading to poor perinatal outcomes. ${ }^{14}$

Therefore, appropriate antenatal care and home-based management of pregnant women of mild PIH on outpatient treatment (rest, salt and restricted diet), knowledge of complication is prerequisite for decreasing maternal mortality attributable to HDP by sensitizing towards better compliance and recognition of danger signs.

The limitations of the study are lack of data of reception of antenatal and intrapartum care received by study participants as they come from wide geographical area and lack of continuity of follow-up at same centre thereby also a lack of details of outcome of pregnancy in each case. Therefore, large study should be planned with adequate sample size to confirm the findings after adjusting for various confounders and following up subjects to outcome of pregnancy to determine the effect of intervention strategy on outcome.at a Secondary Care Birthing unit.

\section{CONCLUSION}

Evidence based guidelines of appropriate antepartum, intrapartum and postpartum care was adopted by Ministry of Health and Family Welfare, Government of India for better perinatal outcomes. But implementation is a big challenge by public and private health facilities.

Therefore, upgradation of health care infrastructure, training of health care staff with hands on training of evidence based practices in structured antenatal counselling, a so far neglected modality of management in early identification of complications of mild PIH to be emphasised and practised.

Engaging community to adopt preventive practices towards improved compliance and care seeking will greatly impact on decreasing maternal mortality rate due to HDP and complications. This intervention will address delay one factor (at community level) of poor seeking behaviour for maternal deaths due to HDP.

\section{ACKNOWLEDGMENTS}

The authors are grateful to Dr. Suvarna, Superintendent, Modern Government Maternity Hospital, Petlaburj, Hyderabad for permitting the conduct of study and Prof. C.R. Shamshad Begum, Ex-Principal, Government College of Nursing, Hyderabad for their valuable guidance.

Funding: No funding sources

Conflict of interest: None declared

Ethical approval: The study was approved by the Institutional Ethics Committee

\section{REFERENCES}

1. Abalos E, Cuesta C, Carroli G, Qureshi Z, Widmer M, Vogel JP et al. Pre-eclampsia, eclampsia and adverse maternal and perinatal outcomes: a secondary analysis of the World Health Organization Multicountry Survey on Maternal and Newborn Health. BJOG. 2014;121 Suppl(s1):14-24.

2. Sajith M, Nimbargi V, Modi A, Sumariya R. Incidence of pregnancy induced hypertension and prescription pattern of antihypertensive drugs in pregnancy. Int J pharma Sci Res. 2014;5(4):163-70.

3. Montgomery AL, Ram U, Kumar R, Jha P. Maternal mortality in India: Causes and healthcare service use based on a nationally representative survey. PLoS One. 2014;9(1):e83331.

4. Umesawa M, Kobashi G. Epidemiology of hypertensive disorders in pregnancy: prevalence, risk factors, predictors and prognosis. Nat Publ Gr. 2016;40(3):213-20.

5. Ye C, Ruan Y, Zou L, Li G, Li C, Chen Y et al. The 2011 survey on hypertensive disorders of pregnancy (HDP) in China: Prevalence, risk factors, complications, pregnancy and perinatal outcomes. PLoS One. 2014;9(6):e100180.

6. Conde-Agudelo A, Belizán JM. Risk factors for preeclampsia in a large cohort of Latin American and Caribbean women. BJOG. 2000;107(1):75-83.

7. Lee CJ, Hsieh TT, Chiu TH, Chen KC, Lo LM, Hung TH. Risk factors for pre-eclampsia in an Asian population. Int J Gynecol Obstet. 2000;70(3):327-33.

8. Abalos E, Cuesta C, Carroli G, Qureshi Z, Widmer $\mathrm{M}$, Vogel $\mathrm{J}$ et al. Pre-eclampsia, eclampsia and adverse maternal and perinatal outcomes: a secondary analysis of the World Health Organization Multicountry Survey on Maternal and Newborn 
Health. BJOG An Int J Obstet Gynaecol. 2014;121(s1):14-24.

9. Timofeev J, Reddy UM, Huang CC, Driggers RW, Landy HJ, Laughon SK. Obstetric complications, neonatal morbidity, and indications for cesarean delivery by maternal age. Obstet Gynecol. 2013;122(6):1184-95.

10. Poon LCY, Kametas NA, Chelemen T, Leal A, Nicolaides KH. Maternal risk factors for hypertensive disorders in pregnancy: a multivariate approach. J Hum Hypertens. 2010;24(2):104-10.

11. Taddei S, Virdis A, Ghiadoni L, Versari D, Salvetti A. Endothelium, aging, and hypertension. Curr Hypertens Rep. 2006;8(1):84-9.

12. Nayak D, Nayak D. Effectiveness of structured teaching programme on pregnancy induced hypertension among primigravida mothers. Int $\mathrm{J}$ Adv Nurs Sci Pract. 2015;2(1):49-53.
13. Souza L. Effectiveness of planned teaching programme on pre-eclampsia for primigravida women in a selected community at Mangalore. 2005 Available http://14.139.159.4:8080/jspui/handle/123456789/14 43

14. Urassa DP, Nystrom L, Carlstedt A, Msamanga GI, Lindmark G. Management of hypertension in pregnancy as a quality indicator of antenatal care in rural Tanzania. Afr J Reprod Health. 2003;7(3):6976.

Cite this article as: Singh N, Ponna SN, Rajeshwari KR. Efficacy of structured teaching programme on home care management of pregnancy induced hypertension in primigravida mothers: a tertiary hospital study. Int J Reprod Contracept Obstet Gynecol 2017;6:3808-12. 